While the series is small, the book can be recommended as a basis upon which to build other similar investigations in view of the fact that the series reported is too small to yield unequivocal evidence of the safety of this procedure, although it is supported by good investigative evidence. Unfortunately, the text is written in German, and there is only a very brief English summary which does not go into details.

\title{
CANADIAN CRITICAL CARE SOCIETY
}

Over the past few months, interested individuals have been attempting to initiate the formation of a Canadian Critical Care Society. This society would be open initially to all physicians interested in critical care medicine, including physicians, surgeons, pediatricians, anesthetists, etc. Close liaison with the Royal College is anticipated, and indeed, the inaugural meeting of this subsection of the College will be at the January 1978 Royal College Meeting in Vancouver, B.C. A one-half-day program is anticipated. The scientific meeting will include an inaugural address by Dr. Bryan Kirk on the history and future of critical care medicine in Canada, and it is hoped that there will be a response in the form of abstracts. The abstracts will be included in the Royal College call for papers, and we will follow their format.

Any individual interested in participating in a group of this sort is asked to contact the Acting Secretary of the Canadian Critical Care Society. The address is published below. Further information will be available as the Society becomes more concrete in form and function.

Adpress: Ronald L. Holliday, M.D., Acting Secretary, Canadian Critical Care Society, Department of Surgery, Victoria Hospital, London, Ontario N6A 4G5. 